criteria for the definition and classification of patients with chronic obstructive pulmonary disease (COPD) [1]. Will it be meaningful to add prebronchodilator values and reversibility to those criteria? It sounds plausible, but I believe it is not justified. The reason for this is that we should distinguish the criteria for the disease from potentially relevant information on the disease.

We all seem to agree that COPD is a disease in which airflow limitation is not fully reversible. The latter points to residual airflow limitation after giving an adequate dose of a bronchodilator: in other words, a lowered ceiling (postbronchodilator value) of spirometry. Would it be helpful to include the reversibility as such? Apart from the different ways of expressing reversibility [2], it appears that the response to a bronchodilator has hardly any diagnostic value for COPD [3], whilst being very poorly reproducible [4]. As indicated in my editorial, this is not unexpected since the prebronchodilator value of forced expiratory volume in one second and, thereby, its reversibility towards the postbronchodilator ceiling value is modulated by variable degrees of smooth muscle contraction. Therefore, the prebronchodilator value, as well as the reversibility, does not seem to be an adequate criterion as to whether airflow limitation is "not fully reversible".

Does this mean that reversibility is a useless index? No, certainly not. The degree of reversibility may point towards clinically and pathophysiologically relevant phenotypes of COPD. What are the determinants of smooth muscle contraction in this disease? We don't know, but there is recent evidence that patients with a substantial degree of reversibility of their airflow limitation (notwithstanding their abnormal postbronchodilator value) do have certain specific characteristics, such as elevated levels of exhaled nitric oxide and sputum eosinophilia [5], together with blood eosinophilia and reduced levels of neutrophil activation [6]. Hence, indeed, there is a message that needs to be taken seriously in measuring reversibility, despite its poor reproducibility [4].

Taken together, when distinguishing the strict criteria for the definition and classification of chronic obstructive pulmonary disease from other potentially useful information on the clinical phenotype of the disease, D. Lee and myself do seem to agree. I thank him for his comments.

\section{P.J. Sterk}

Leiden, The Netherlands.

\section{References}

1. Sterk PJ. Let's not forget: the GOLD criteria for COPD are based on post-bronchodilator FEV1. Eur Respir J 2004; 23: 497-498.

2. Brand PLP, Quanjer PH, Postma DS, et al. Interpretation of bronchodilator response in patients with obstructive airways disease. The Dutch Chronic Non-Specific Lung Disease (CNSLD) study group. Thorax 1992; 47: 429-436.

3. Meslier N, Racineux JL, Six P, Lockhart A. Diagnostic value of reversibility of chronic airway obstruction to separate asthma from chronic bronchitis: a statistical approach. Eur Respir J 1989; 2: 497-505.

4. Calverley PMA, Burge PS, Spencer S, Anderson JA, Jones PW. Bronchodilator reversibility testing in chronic obstructive pulmonary disease. Thorax 2003; 58: 659-664.

5. Papi A, Romagnoli M, Baraldo S, et al. Partial reversibility of airflow limitation and increased exhaled NO and sputum eosinophilia in chronic obstructive pulmonary disease. $\mathrm{Am}$ J Respir Crit Care Med 2000; 162: 1773-1777.

6. Sitkauskiene B, Sakalauskas R, Malakauskas K, Lötvall J. Reversibility to a beta2-agonist in COPD: relationship to atopy and neutrophil activation. Respir Med 2003; 97: 591598

\title{
Additive blockade of $\beta_{2}$-integrin adhesion of eosinophils by salmeterol and fluticasone propionate
}

\author{
To the Editor:
}

In their report of the effects of fluticasone propionate and salmeterol on eosinophil adhesion, Myo et al. [1] correctly considered that fluticasone propionate may have reduced eosinophil adhesion by inducing apoptosis [2-5], but they did not perform the appropriate experiments to test this. Assessment of "cell viability" by exclusion of membraneimpermeant dyes such as trypan blue or propidium iodide will not identify apoptotic eosinophils, which generally have intact plasma membranes [6]. Appropriate methods to quantify eosinophil apoptosis include examination of nuclear morphology and annexin V staining, which if performed would probably have resulted in a different interpretation of the data. Apoptotic cells are clearly not "viable" because cellular functions (including cell adhesion) are significantly impaired. Unfortunately, the term "cell viability" is widely used in scientific literature, but it is imprecise and should be abandoned.

\section{S.P. Hart}

MRC Centre for Inflammation Research, University of Edinburgh Medical School, Edinburgh, UK.

\section{References}

1. Myo S, Zhu X, Myou S, et al. Additive blockade of $\beta_{2^{-}}$ integrin adhesion of eosinophils by salmeterol and fluticasone propionate. Eur Respir J 2004; 23: 511-517.

2. Whyte MKB, Meagher LC, MacDermot J, Haslett C. Impairment of function in aging neutrophils is associated with apoptosis. J Immunol 1993; 150: 5124-5134.

3. Dransfield I, Stocks SC, Haslett C. Regulation of cell adhesion molecule expression and function associated with neutrophil apoptosis. Blood 1995; 85: 3264-3273.

4. Meagher LC, Cousin JM, Seckl JR, Haslett C. Opposing effects of glucocorticoids on the rate of apoptosis in neutrophilic and eosinophilic granulocytes. $J$ Immunol 1996; 156: 4422-4428.

5. Zhang X, Moilanen E, Kankaanranta H. Enhancement of human eosinophil apoptosis by fluticasone propionate, budesonide, and beclomethasone. Eur J Pharmacol 2000; 406: 325-332.

6. Stern M, Meagher LC, Savill JS, Haslett C. Apoptosis in human eosinophils: programmed cell death in the eosinophil leads to phagocytosis by macrophages and is modulated by IL-5. J Immunol 1992; 148: 35433549 . 